\title{
Sensitivity and specificity of the Mini-Mental State Exam in the diagnosis of dementia
}

\author{
L. Sabe' ${ }^{1}$ L. Jason ${ }^{1}$, M. Juejati ${ }^{1}$, R. Leiguarda ${ }^{2}$ and S. Starkstein ${ }^{1,2}$ \\ Departments of ${ }^{1}$ Behavioral Neurology and ${ }^{2}$ Clinical Neurology, Raúl Carrea Institute of \\ Neurological Research, Buenos Aires, Argentina \\ Correspondence to: S.E. Starkstein, Instituto de Investigaciones Neurológicas Raúl Carrea, \\ Ayacucho 2166, 1112 Buenos Aires, Argentina
}

\begin{abstract}
The Mini-Mental State Exam (MMSE) is a brief cognitive test that assesses several cognitive domains, such as orientation, attention, concentration, memory, language, and constructional abilities. While the MMSE was found to be valid and reliable in the diagnosis of moderate dementia, its sensitivity and specificity for the diagnosis of mild dementia has been rarely examined. We assessed the specificity and sensitivity of the MMSE in a consecutive series of 44 patients with mild dementia, and a group of age-comparable normal controls. While the specificity of the MMSE for the diagnosis of mild dementia was very high $(100 \%)$, the sensitivity was only $55 \%$ [ 20 of the 44 patients with mild dementia had an MMSE score in the normal range ( $\geqslant 26$ points)]. On the other hand, the assessment with both the Buschke Selective Reminding and the Boston Naming tests discriminated mild Alzheimer's disease patients with normal MMSE scores from controls with a sensitivity and specificity of $64 \%$. In conclusion, the assessment with verbal memory and naming tasks provided a significantly more sensitive measure of early dementia than the MMSE.
\end{abstract}

Keywords: Alzheimer's disease - Dementia - Mini-Mental State Exam

\section{INTRODUCTION}

Dementia is a highly prevalent disease among elderly individuals. While the mental status evaluation is a critical part of the diagnosis of dementia, most neuropsychological batteries, such as the Wechsler Adult Intelligence Scale (Wechsler, 1955), usually take several hours to complete. Folstein et al. (1975) developed the Mini-Mental State Exam (MMSE) as an easily administered test that can be completed in 10-15 min, and samples important cognitive domains, such as orientation, attention-concentration, recall, language, and constructional praxis.

While the MMSE has been found to be a valid and reliable instrument for the diagnosis of moderate dementia (Folstein et al., 1975), several studies suggest it may not be useful in the diagnosis of mild dementia (Knopman and Ryberg, 1989; Galasko et al., 1990; Welsh et al., 1991). The aim of the present study was to examine the sensitivity and specificity of the MMSE in the diagnosis of mild dementia, and to determine whether a brief neuropsychological battery that included tests of verbal naming, verbal memory, verbal comprehension, verbal fluency, and nonverbal abstract reasoning had a better sensitivity and specificity.

\section{METHODS}

\section{Patients}

We examined a consecutive series of 44 patients attending the Neurology Outpatient Unit of our Institute, who met the NINCDS-ADRDA (McKhann et al., 1984) criteria for probable Alzheimer's disease (AD) and the DSM-III-R (APA, 1987) criteria for mild dementia. Every patient underwent a clinical and laboratory evaluation to rule out other causes of dementia. Additional inclusion criteria were: (1) no focal cerebral lesions on the CT scan; (2) a Hachinski Ischemic score $\leqslant 4$ (Hachinski et al., 1975); and (3) no history of closed head injuries with loss of consciousness, strokes, or other neurologic disorders with central nervous system involvement. A series of 14 controls, who were mostly spouses of $\mathrm{AD}$ patients, were also examined. None of them had neurological or psychiatric disorders, and all of them had a normal CT scan.

\section{Neurological examination}

After informed consent, patients had a comprehensive neurological evaluation, which included a standardized questionnaire that assessed the onset and duration of illness, the presence of impairments in activities of daily 
living, and limitations in work and social activities. The same interviewer assessed patients and controls with the Mini-Mental State Exam (MMSE).

\section{Neuropsychological examination}

Blind to group membership, demographic data, and MMSE scores, both patients and controls had a neuropsychological evaluation that consisted of the following tasks.

Buschke Selective Reminding Test (Buschke and Fuld, 1974): this test measures verbal learning and memory during a multiple-trial list learning task. The outcome measure was the long-term retrieval (LTR) score.

Token Test(De Renzi and Faglioni, 1978): this test measures verbal comprehension of commands of increasing complexity.

Boston Naming Test (Kaplan et al., 1983): this test measures the ability to name pictured objects.

Controlled Oral Word Association Test (Benton, 1968): this test examines the spontaneous production of words beginning with the letters F, A, and S.

Raven's Progressive Matrices(Raven et al., 1986): this test measures reasoning in the visual modality.

\section{Statistical analysis}

Statistical analysis was carried out using means and S.D., two-way analysis of variance (ANOVA) with repeated measures, and post-hoc $t$-tests. Sensitivity and specificity of cognitive tests were examined with a discriminant function analysis. All $p$ values are two-tailed.

TABLE I. Demographic findings

\begin{tabular}{|c|c|c|c|}
\hline & $\begin{array}{c}\text { Mild dementia } \\
\text { with MMSE } \\
<26\end{array}$ & $\begin{array}{l}\text { Mild dementia } \\
\text { with MMSE } \\
\geqslant 26\end{array}$ & $\begin{array}{l}\text { Control } \\
\text { group }\end{array}$ \\
\hline $\begin{array}{c}\text { Number of } \\
\text { patients }\end{array}$ & 24 & 20 & 14 \\
\hline Age (mean years) & $74.1(6.9)$ & $70.7(6.5)$ & $68.3(8.8)$ \\
\hline Sex (\% females) & 67 & 75 & 57 \\
\hline $\begin{array}{l}\text { Education (mean } \\
\text { years) }\end{array}$ & $8.6(5.0)$ & $12.7(4.0)$ & $12.5(4.0)$ \\
\hline $\begin{array}{l}\text { Duration of illness } \\
\text { (mean years) }\end{array}$ & $3.4(1.9)$ & $3.9(2.3)$ & - \\
\hline
\end{tabular}

S.D.s are in parentheses.
TABLE II. Neuropsychological findings

\begin{tabular}{lccc}
\hline & $\begin{array}{c}\text { Mild dementia } \\
\text { with MMSE } \\
<26\end{array}$ & $\begin{array}{c}\text { Mild dementia } \\
\text { with MMSE } \\
\geqslant 26\end{array}$ & $\begin{array}{c}\text { Control } \\
\text { group }\end{array}$ \\
\hline $\begin{array}{c}\text { MMSE scores } \\
\text { (mean) }{ }^{1}\end{array}$ & $20.5(3.9)$ & $27.3(1.3)$ & $28.0(1.2)$ \\
$\begin{array}{c}\text { Buschke Selective } \\
\text { RT }\end{array}$ & $1.8(1.9)$ & $4.1(2.6)$ & $6.5(3.0)$ \\
$\begin{array}{c}\text { Boston Naming } \\
\text { Test }{ }^{1,2}\end{array}$ & $12.7(5.4)$ & $16.3(3.1)$ & $19.2(0.7)$ \\
$\begin{array}{l}\text { Raven's } \\
\text { Progressive } \\
\text { Matrices }{ }^{1,2}\end{array}$ & $38.7(27.0)$ & $50.2(36.1)$ & $73.3(23.7)$ \\
$\begin{array}{l}\text { Word-controlled } \\
\text { Test }{ }^{1}\end{array}$ & $27.2(6.8)$ & $34.1(11.5)$ & $39.8(10.3)$ \\
Token Test $^{1}$ & $17.9(6.4)$ & $21.6(4.6)$ & $24.3(1.3)$ \\
\hline
\end{tabular}

S.D.s are shown in parentheses.

'Dementia with MMSE $<26$ vs controls, $p<0.01$.

${ }^{2}$ Dementia with MMSE $\geqslant 26$ vs controls, $p<0.05$.

\section{RESULTS}

\section{Demographic findings (Table I)}

Based on MMSE scores, AD patients were divided into those with normal ( $\geqslant 26$ points) and abnormal $(<26$ points) MMSE scores. We used a cut-off score on the MMSE of 26 points instead of the usual of 25 points so as to select a group of $\mathrm{AD}$ patients where the use of the MMSE would clearly be unhelpful.

No significant differences were found in age, sex, and years of education between $\mathrm{AD}$ patients and controls.

Neuropsychological findings (Table II)

Using a cut-off score of 26 points on the MMSE, all the controls had a normal MMSE score, compared with 20 of the 44 patients (45\%) with mild dementia. While the specificity of the MMSE for the diagnosis of dementia was $100 \%$, the sensitivity was only $55 \%$. Due to this low sensitivity of the MMSE, we examined whether other cognitive tasks had a higher sensitivity. Thus, we compared the 20 patients with mild dementia and MMSE score $\geqslant 26$ with 14 age- and MMSE-comparable normal controls (Tables I and II). A two-way ANOVA with repeated measures [Factor 1: group (AD vs controls), repeated measure: neuropsychological tasks] showed a significant group effect $[\mathrm{F}(1,32)=10.9, p=0.002]$ (AD patients showed an overall worse performance on the neuropsychological battery than the normal controls), and a significant group $\times$ task interaction $[\mathrm{F}(4,112)=3.90, p=0.005]$ (Table II). A post-hoc analysis showed that the group with mild 
dementia and normal MMSE scores had significantly worse performances on the Buschke long-term retrieval $(p=0.002)$, Boston Naming Test $(p<0.05)$, and Raven's Progressive Matrices $(p<0.05)$ than the control group. In order to examine which of these tasks better separated $\mathrm{AD}$ patients from normal controls, a discriminant function analysis was carried out. Both the Boston Naming Test and the Buschke Selective Reminding Test, had a significant discriminant power (Wilks' $=0.75, p=0.009$, and Wilks' $=0.69, p<0.05$, respectively), showing both a sensitivity and specificity of $64 \%$ for the diagnosis of mild dementia among patients with an MMSE score $\geqslant 26$.

\section{DISCUSSION}

The present study showed two important findings. First, the MMSE had a high specificity $(100 \%)$ but a low sensitivity $(55 \%)$ for the diagnosis of mild dementia. Second, when patients with mild dementia and normal MMSE scores were compared on a brief neuropsychological battery with age-comparable normal controls with similar MMSE scores, patients with mild dementia showed significant deficits on anterograde verbal memory and naming tasks.

The MMSE is a cognitive evaluation that taps different cognitive domains, has a high reliability, and needs a brief time for completion. While this instrument is used by clinicians for research and clinical assessments, recent studies suggest the MMSE may not be sensitive for the diagnosis of mild dementia. Galasko et al. (1990) found that 24 of 74 patients with mild AD had MMSE scores $>23$ (i.e. a sensitivity of $68 \%$ ). Similarly, our study demonstrated a high specificity among patients with mild dementia, but a low sensitivity since 20 of 44 patients (45\%) had an MMSE score $\geqslant 26$.

Other neuropsychological tasks may be more effective for the diagnosis of mild dementia, and this possibility was explored in several recent studies. Storandt et al. (1984) assessed 42 patients with a large neuropsychological battery and found that the Logical Memory subtest of the Wechsler Memory Scale (WMS) (Wechsler, 1945), the Trail Making Test (a test of visual scanning and graphomotor speed) (Reitan, 1958), the Controlled Oral WordAssociation Test (a test of verbal fluency), and the Mental Control subtest of the WMS (which involves sequenced cognition with a verbal response) adequately classified all patients with mild $\mathrm{AD}$ and normal controls. However, MMSE scores in patients with mild $\mathrm{AD}$ were not reported.

Knopman and Ryberg (1989) assessed the MMSE and a short neuropsychological battery that included the Symbol-Digit Modalities Test (Smith, 1973), the Raven's Progressive Matrices, and a delayed word recall task in a group of 28 patients with mild AD. They found that all three neuropsychological tasks classified patients and normal controls with a sensitivity of $100 \%$ and a specificity of $93 \%$. This high rate of correct classification may be related to the fact that the $\mathrm{AD}$ group included patients with MMSE scores $>18$, while we assessed our cognitive battery in AD patients with MMSE scores $\geqslant 26$. In a recent study, Robinson-Whelen and Storandt (1992) demonstrated the importance of verbal delayed recall in the diagnosis of early dementia. They compared 51 patients with very mild dementia and 64 controls using the Logical Memory subtest of the WMS, and found that patients with very mild dementia recalled significantly less information in both the immediate and delayed conditions than the controls. Flicker et al. (1991) have also examined neuropsychological differences between patients with mild dementia and normal controls and found that patients with mild dementia had significantly more impairments on tests of recent and remote memory, language function, concept formation, and visuospatial tasks. However, neither Robinson-Whelen and Storandt nor Flicker et al. restricted their cognitive assessment to patients with mild dementia and normal MMSE scores. Welsh et al. (1991) examined a series of 49 patients with mild dementia and MMSE score $\geqslant 24$ with a brief neuropsychological battery that included tests of language, constructional praxis, and verbal memory. They found that delayed memory proved to be the most effective task to distinguish mild dementia from normal controls, and naming was useful in confirming the presence of dementia and staging the disease. When our 20 patients with mild dementia were compared with 14 age- and MMSE-comparable normal controls, patients with mild dementia and normal MMSE scores showed a significantly worse performance on a brief neuropsychological battery that included tests of verbal memory, naming, verbal comprehension, verbal fluency, and non-verbal (abstract) reasoning. A discriminant function analysis demonstrated that the Buschke Verbal Reminding Test (a measure of anterograde verbal memory) and the Boston Naming Test significantly discriminated patients with mild dementia and normal MMSE scores from normal controls. Patients with mild dementia and a normal MMSE score also showed significantly lower scores on the Raven's Progressive Matrices (which assesses abstract reasoning) than the control group. However, the inclusion of this test in the discriminant function analysis did not improve the discriminant power. Finally, there were no significant differences between patients with mild dementia and normal controls in either the Token Test or the verbal fluency task.

In conclusion, the present findings suggest that a brief neuropsychological assessment that includes the MMSE, the Buschke Verbal Reminding Test, and the Boston Naming Test provides the highest sensitivity and specificity for the diagnosis of mild dementia in patients with probable $\mathrm{AD}$. 


\section{Acknowledgements}

This work was partially supported by grants from the Sandoz Foundation and the Raúl Carrea Institute of Neurological Research. We thank Jason Brandt, Ph.D., for his most valuable suggestions.

\section{REFERENCES}

APA (1987) Diagnostic and Statistical Manual of Mental Disorders-Revised. American Psychiatric Press, Washington, DC.

Benton AL (1968) Differential behavioral effects in frontal lobe disease. Neuropsychologia, 6, 53-60.

Buschke H and Fuld PA (1974) Evaluating storage, retention, and retrieval in disordered memory and learning. Neurology, 24, 1019-1025.

De Renzi E and Faglioni P (1978) Development of a shortened version of the Token Test. Cortex, 14, 41-49.

Flicker C, Ferris SH and Reisberg B (1991) Mild cognitive impairment in the elderly: predictors of dementia. Neurology, 41, 1006-1009.

Folstein MF, Folstein SE and McHugh PR (1975) Mini-Mental state: a practical method for grading the cognitive state of patients for the clinician. Journal of Psychiatry Research, 12, 189-198.

Galasko D, Klauber MR, Hofstetter R, Salmon DP, Lasker B and Thal LJ (1990) The Mini-Mental State Examination in the early diagnosis of Alzheimer's disease. Archives of Neurology, 47, 49-52.

Hachinski VC, Iliff LD, Zilhka L, Du Boulay GH, McAllister VL, Marshall J, Russell RWR and Symon L (1975) Cerebral blood flow in dementia. Archives of Neurology, 40, 97-103.

Kaplan EF, Goodglass H and Weintraub S (1983) The Boston Naming Test. Lea \& Febiger, Philadelphia.
Knopman DS and Ryberg S (1989) A verbal memory test with high predictive accuracy for dementia of the Alzheimer type. Archives of Neurology, 46, 141-145.

McKhann G, Drachman D, Folstein MF, Katzman R, Price D and Stadlan EM (1984) Clinical diagnosis of Alzheimer's disease: report of the NINCDS-ADRDA Work Group under the auspices of Department of Health and Human Services Task Force on Alzheimer's Disease. Neurology, 34, 939-944.

Raven JC, Court JH and Raven J (1986) Manual for Raven's Progressive Matrices and Vocabulary Scales. H.K. Lewis \& Co., London.

Reitan RM (1958) Validity of the Trail Making Test as an indicator of organic brain damage. Perceptual and Motor Skills, $\mathbf{8}$, 271-276.

Robinson-Whelen S and Storandt M (1992) Immediate and delayed prose recall among normal and demented adults. Archives of Neurology, 49, 32-34.

Smith A (1973) Symbol Digit Modalities Test. Manual. Western Psychological Services, Los Angeles.

Storandt M, Botwinick J, Danziger WL, Berg L and Hughes CP (1984) Psychometric differentiation of mild senile dementia of the Alzheimer type. Archives of Neurology, 41, 497-499.

Wechsler D (1945) A standardized memory scale for clinical use. Journal of Psychology, 19, 87-95.

Wechsler D (1955) Wechsler Adult Intelligence Scale Manual. Psychological Corporation, New York.

Welsh K, Butters N, Hughes J, Mohs R and Heyman A (1991) Detection of abnormal memory decline in mild cases of Alzheimer's disease using CERAD neuropsychological measures. Archives of Neurology, 48, 278-281.

(Received 30 September 1993; accepted 10 October 1993) 


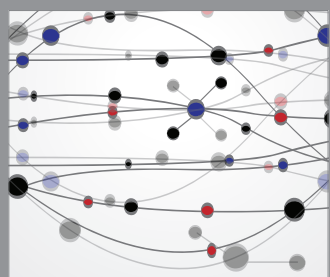

The Scientific World Journal
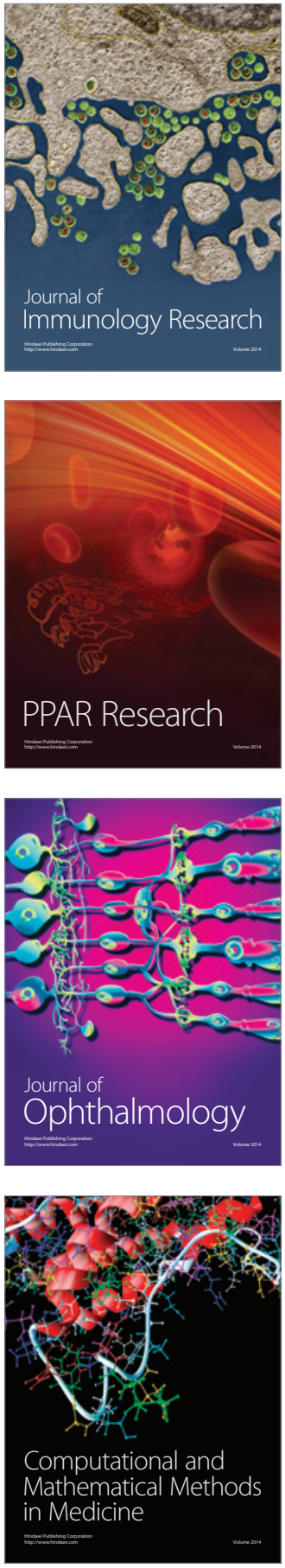

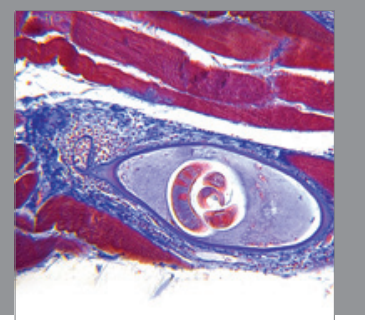

Gastroenterology

Research and Practice
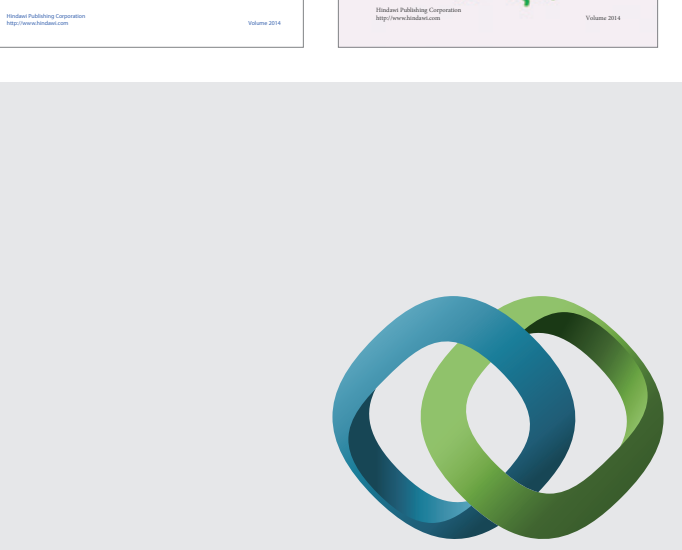

\section{Hindawi}

Submit your manuscripts at

http://www.hindawi.com
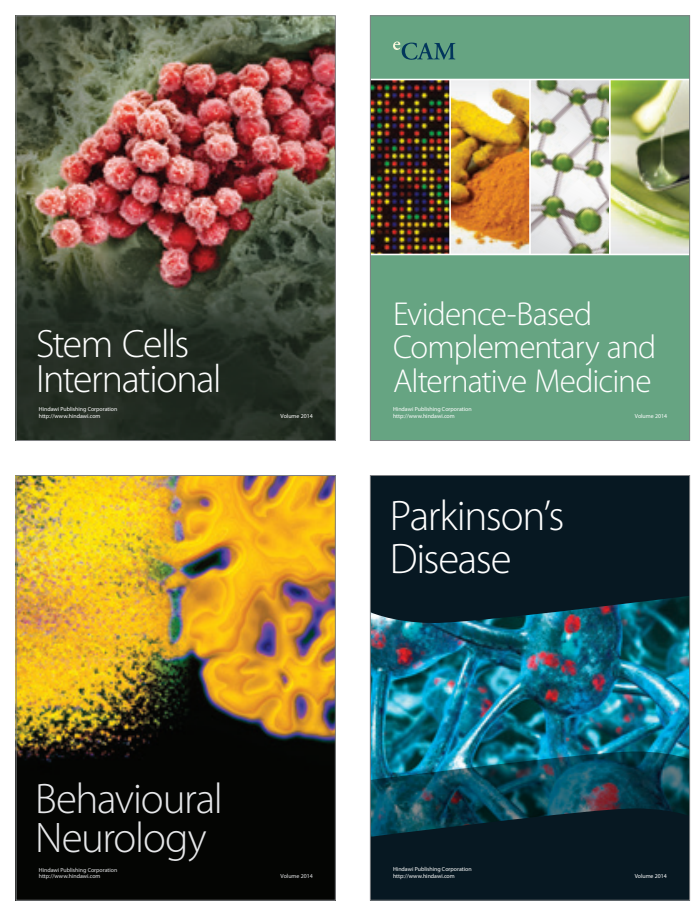

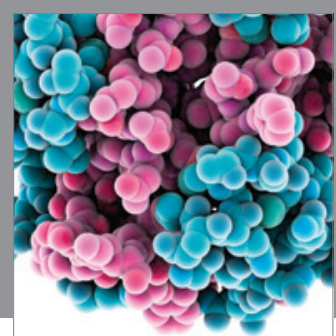

Journal of
Diabetes Research

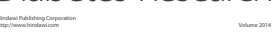

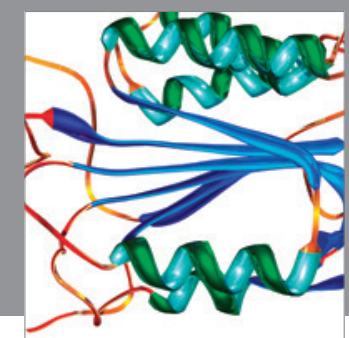

Disease Markers
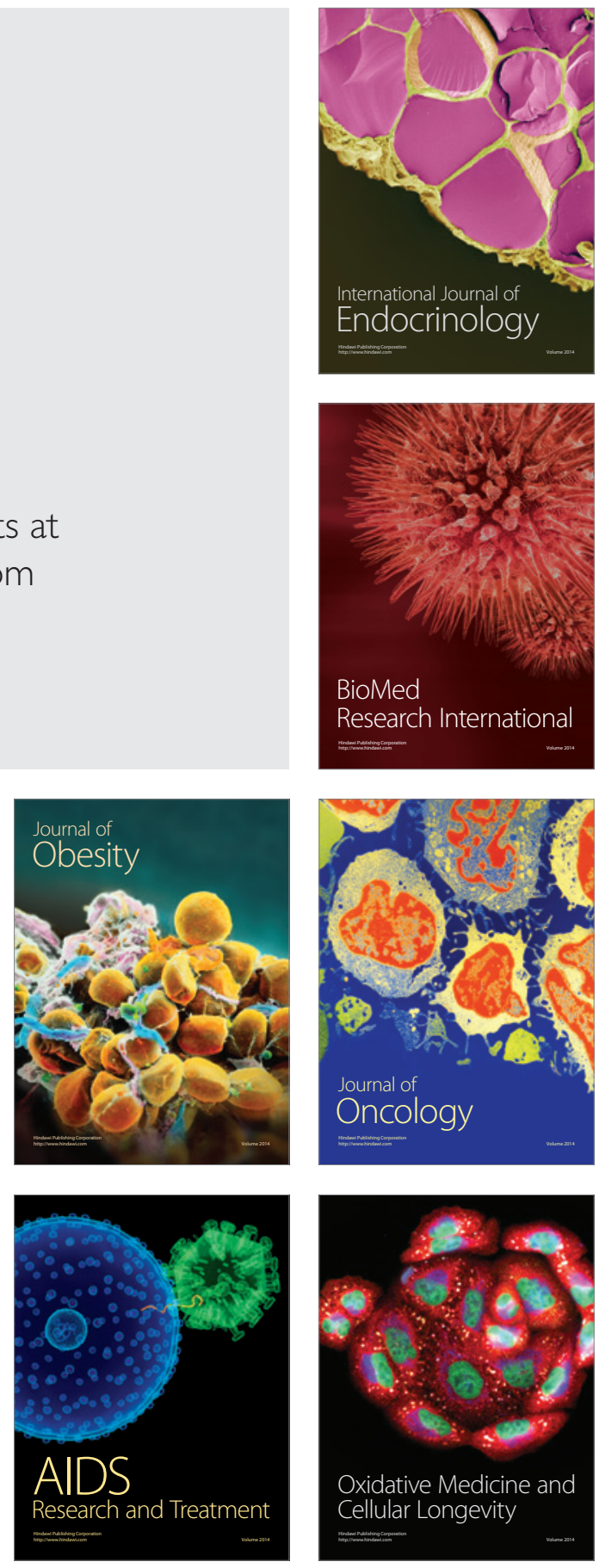